\title{
MONTEGGIA INJURIES IN CHILDREN
}

\author{
J. J. WILEY, J. P. GALEY
}

From the Children's Hospital of Eastern Ontario, Ottawa

Forty-six children with Monteggia fracture-dislocations have been studied. The circumstances of the accident could rarely be recalled so that the mechanism of injury remains unclear. The study did, however, confirm the importance of conservative management of the injury in children; unlike the adult variety, this gave very satisfactory results. Our review also supports the classification into three basic types of Monteggia lesion according to the direction of displacement of the dislocated radial head. For simplicity, all other types, variations or equivalents can be regarded as belonging to these basic patterns; in particular we include those controversial cases in which the radiohumeral dislocation is combined with a fractured olecranon.

Monteggia injuries, so easily diagnosed in adults, are often missed in children. However, if correctly diagnosed and conservatively treated, the outcome is usually better.

We have reviewed 46 cases of Monteggia fractures in children seen during the past 14 years, and investigated the existing classification, the mechanisms of injury, the methods of treatment and the results.

The injury was first described by Giovanni Monteggia in 1814, who noted that it included a fracture of the ulna in its superior portion and a dislocation of the head of the radius. either anteriorly or posteriorly (Peltier 1957). Little was written about it subsequently until Cunningham (1934) reiterated its importance, saying that it warranted "special mention". In 1940, Speed and Boyd reported their experience with 62 patients; at that time treatment differed according to whether the injury was recent or old. These authors advocated closed reduction as the treatment of choice for acute injuries in children, but pointed out that closed methods usually failed in adults. They also described the lateral variety of radial head dislocation and even included associated fractures of the olecranon process of the ulna. To some surgeons involvement of the olecranon meant that the injury was not a true Monteggia fracture-dislocation. Bruce, Harvey and Wilson (1974), for example, specifically excluded olecranon fractures.

Nevertheless, a number of variations of Monteggia fractures and dislocations were recognised by Bado (1962), who described an extensive classification according to the direction of dislocation of the radial head (Fig. 1). In Type I dislocation was anterior, in Type II posterior and in Type III lateral. He also added a fourth type

J. J. Wiley, MD, FRCS(C), Associate Professor of Surgery (Orthopaedics), University of Ottawa

J. P. Galey, MD, Resident

Division of Orthopaedic Surgery. Children's Hospital of Eastern

Ontario, 401 Smyth Road, Ottawa, Ontario, Canada K1H 8L1.

Requests for reprints should be sent to Dr J. J. Wiley.

( 1985 British Editorial Society of Bone and Joint Surgery $0301-620 \times 855161 \$ 2.00$
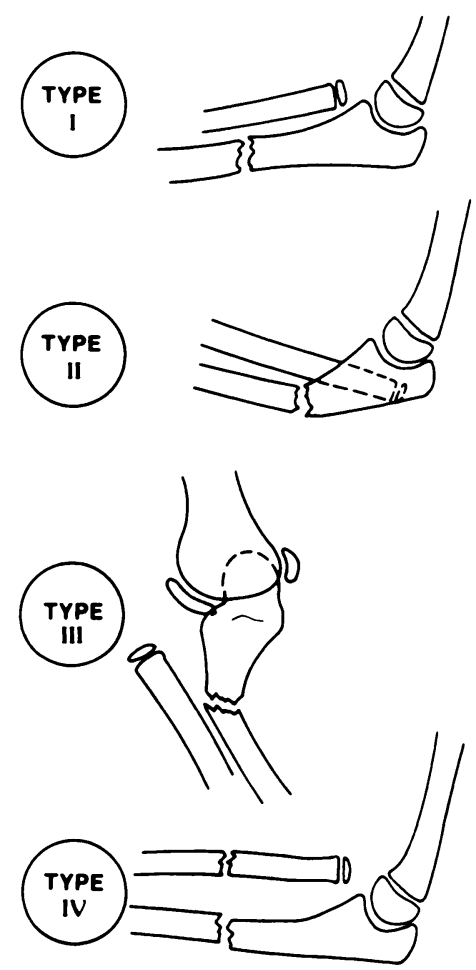

Fig. 1

Bado's classification (1962) of Monteggia lesions.
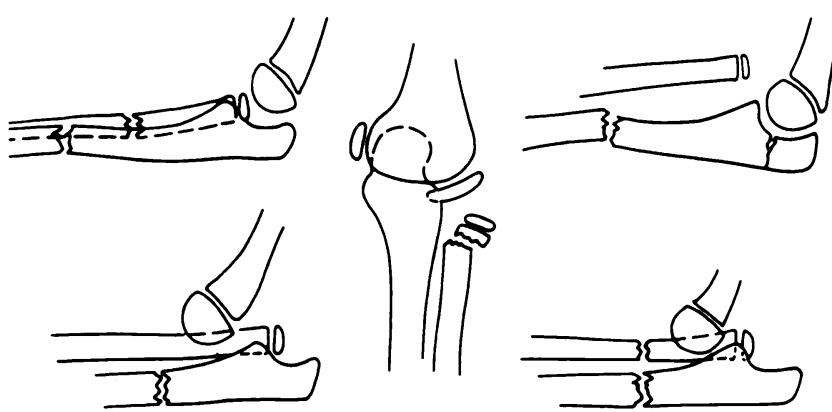

Fig. 2

Bado’s Monteggia "equivalent" lesions. 
Table I. Details of our 46 patients, using Bado's classification

\begin{tabular}{|c|c|c|c|c|}
\hline Injury & Cases & $\%$ & $\begin{array}{l}\text { Equiva- } \\
\text { lents }\end{array}$ & $\begin{array}{l}\text { Olecranon } \\
\text { fractures }\end{array}$ \\
\hline $\begin{array}{l}\text { Type I } \\
\text { Anterior dislocation of } \\
\text { radial head } \\
\text { Fractured shaft of ulna }\end{array}$ & 22 & 48 & 2 & 5 \\
\hline $\begin{array}{l}\text { Type II } \\
\text { Posterior dislocation of } \\
\text { radial head } \\
\text { Fractured shaft of ulna }\end{array}$ & 5 & 11 & 2 & 2 \\
\hline $\begin{array}{l}\text { Type III } \\
\text { Lateral dislocation of } \\
\text { radial head } \\
\text { Fractured shaft of ulna }\end{array}$ & 18 & 39 & 3 & 12 \\
\hline $\begin{array}{l}\text { Type IV } \\
\text { Anterior dislocation of } \\
\text { radial head } \\
\text { Fractured shafts of both } \\
\text { forearm bones }\end{array}$ & 1 & 2 & & \\
\hline
\end{tabular}

in which, in addition to anterior dislocation of the radial head, the shafts of both forearm bones were fractured; this combined injury hardly warrants separate classification as it is merely a Monteggia injury combined with a forearm fracture. Bado also supplemented his classification to accommodate many unusual varieties which he called "equivalents", or Monteggia-like lesions (Fig. 2).

\section{PATIENTS AND METHODS}

Between 1969 and 1984, 46 children were seen with Monteggia lesions (19 girls and 27 boys) and were available for study. Their ages ranged from 3 years 5 months to 17 years (average age, 7 years 6 months). With the exception of one patient with a Type I injury, who described a direct blow to the ulnar shaft, the method of injury was impossible to ascertain from the patient's description. Thirty-two fell from a height and were injured when the outstretched arm struck the ground. Ten patients simply tripped or stumbled, falling to the ground; four were involved in road accidents and could not recall how the injury occurred.

Five patients had other injuries of the same limb: three had fractures of the distal forearm, one had a supracondylar fracture, and one a fracture of the lateral condyle of the humerus.

Five patients had associated nerve injuries: three to the radial nerve, one to the anterior interosseous nerve, and one to the posterior interosseous nerve. Three patients had associated head injuries, and one suffered major brain damage. Only two patients sustained open fractures, both of the ulna.

Using Bado's classification, all four types of injury were identified in this study (Table I); some were further defined as "equivalent" injuries, that is, lesions with certain features of a Monteggia fracture-dislocation. In our opinion, very few of Bado's "equivalent" injuries can be fairly included in the Monteggia fracture category; consequently, our case material excludes such injuries as

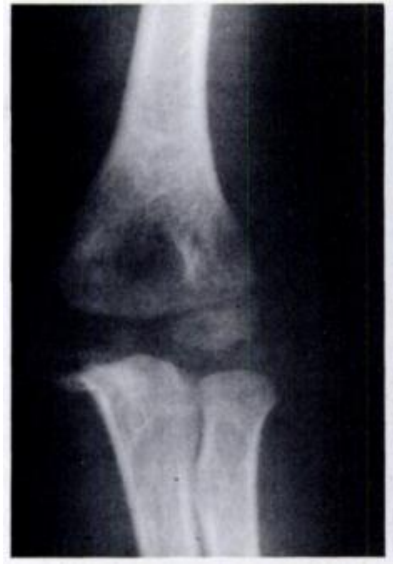

Fig. 3

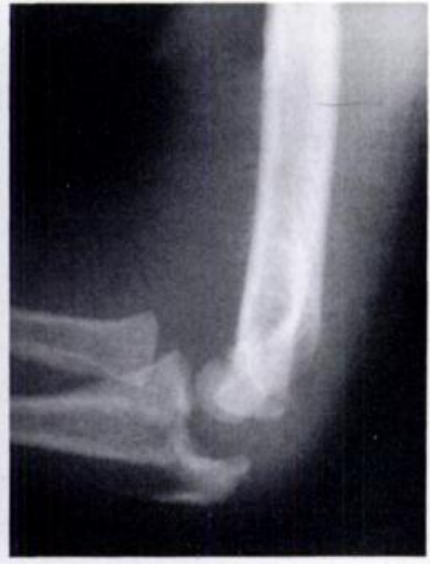

Fig. 4
Case I. A Type I (anterior) Monteggia lesion, including a fracture of the olecranon.

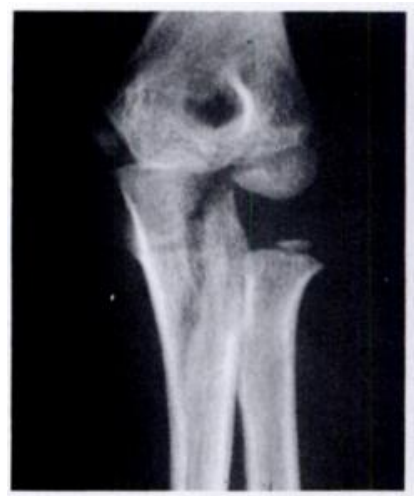

Fig. 5

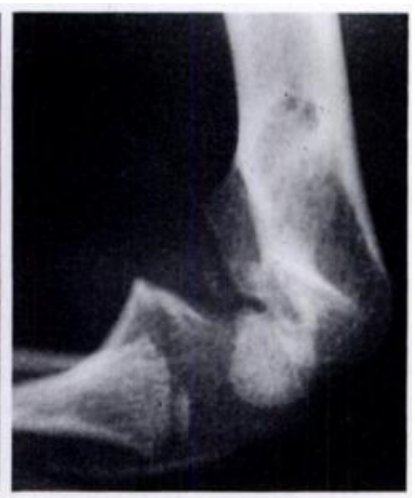

Fig. 6
Case 2. A Type II (posterior) Monteggia lesion and intra-articular ulnar fracture.

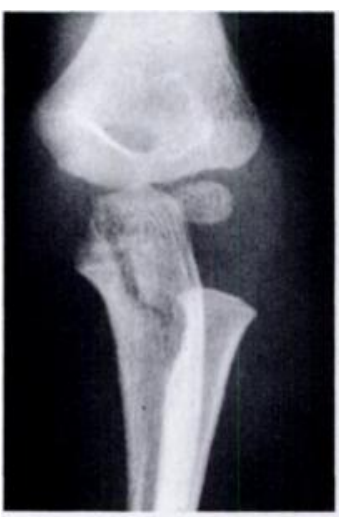

Fig. 7

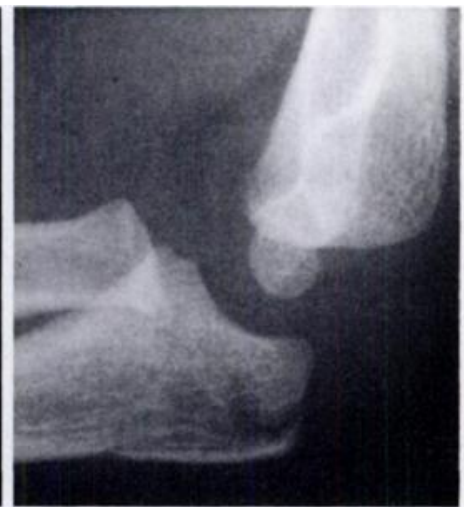

Fig. 8
Case 3. A Type III (lateral) Monteggia fracture with an olecranon fracture.

isolated radial head dislocations, isolated radial neck fractures, and certain fractures of both forearm bones.

Unlike Bruce et al. (1974), we have included the combination of radial head dislocations with olecranon fractures in our series; they are grouped with the three major types (Figs 3 to 8 ) which are exemplified in the following cases.

Case 1 (Figs 3 and 4). A young boy, aged 8 years 3 months, was struck by a car and sustained a Type I 
Monteggia fracture as well as a severe head injury. The radiographs showed an olecranon fracture and an anterior dislocation of the radial head. The elbow injury was treated by open reduction and intramedullary pin fixation of the ulna. Spontaneous reduction of the radius occurred with repositioning of the ulna, possibly due to an intact annular ligament (Wiley, Pegington and Horwich 1974).

Case 2 (Figs 5 and 6). A six-year-old girl fell from a stool onto her outstretched right arm. The diagnosis was made six days after injury, and radiographs showed posterior displacement of the radial head which we judged a Type II Monteggia injury. Closed reduction was successful and, at five-year follow-up, no abnormality could be detected on examination.

Case 3 (Figs 7 and 8). A boy aged 3 years 8 months fell from a tree and sustained a lateral (Type III) Monteggia injury, the ulnar fracture also involving the olecranon. In addition, he sustained a displaced fracture of the distal forearm on the same side. He was treated by closed reduction and immobilised in flexion and supination. At a six-year follow-up, a 5 loss of carrying angle and hyperextension of the elbow were noted.

The frequent association of lateral head dislocations (Figs 7 and 8) with olecranon fractures has been recorded in recent literature and has gradually acquired a rightful place in the classification of Monteggia injuries (Wise 1941; Hume 1957; Beddow and Corkery 1960; Wright 1963; Bado 1967; Boyd and Boals 1969; Theodorou 1969; Germain 1976; Mullick 1977; Peiró, Andres and Fernandez-Esteve 1977).

Treatment. Thirty-five patients had their injuries treated by closed reduction. In two cases, the closed reduction was stabilised by percutaneous intramedullary pinning of the ulnar fracture. Primary open reduction was performed in nine cases because of the complexity (comminution) of the injury, so that reduction was likely to be unstable; in four other cases there was a delay in diagnosis of four to 10 days, and two of these subsequently required open reduction.

The most stable position after closed reduction was combined supination and elbow flexion, regardless of the original direction of displacement (Iselin, Rigault and Judet 1966). After approximately three weeks' immobilisation, active movement was begun.

\section{RESULTS}

During the immediate post-reduction period (less than one month), all nerve injuries recovered spontaneously, and none needed to be explored. One patient had a pin track infection (from an intramedullary Kirschner wire) which resolved without affecting the final result. One patient redislocated after closed reduction but this was not recognised until the plaster splint was removed after 24 days. This patient also had a fracture of the lateral condyle of the humerus in the same arm; he was success- fully treated by open reduction and plate fixation of the ulnar fracture.

Thirty-one patients were followed for more than one year after fracture; the average follow-up was 3.8 years. The remaining 15 patients had a shorter follow-up period, largely due to satisfactory recovery and subsequent failure to keep appointments; in some cases an attempt to evaluate recovery by telephone was unsuccessful. One patient died from injuries sustained in a road accident shortly after her elbow injury.

The patients were assessed for recovery of function, range of movement and carrying angle; late radiographic changes were also assessed in 27 patients, special attention being paid to epiphysial maturation. Other than occasional minor discomfort, no patient had significant complaints or was aware of any loss of function. Objectively, minor deficits in the range of movement were found, and one unexpected finding was increased hyperextension of $5^{\circ}$ to $10^{\circ}$ in 12 patients. Comparative measurements were made of the radial physis, the radial metaphysis, the capitellar axis, the trochlea, the olecranon apophysis and the medial epicondylar axis of both arms. Increased epiphysial maturation on the affected side was a common finding, but of such minimal degree that it had no effect on elbow function. Ulnar bowing at the site of the healed ulnar fracture was noted in 13 instances, although this was impossible to measure accurately on a one-plane radiograph; this bowing had no apparent effect on forearm movements. Persistent subluxation of the radial head ranging from $3 \mathrm{~mm}$ to $6 \mathrm{~mm}$ was noted in four cases: three were subluxated laterally and one medially. This did not affect elbow joint movement, and may have been, not true joint subluxation, but the result of eccentric development of the ossific nucleus of the radial head after injury.

Unlike those reported from studies of Monteggia fracture in adults (Reckling 1982), our results in treating paediatric lesions were very satisfactory.

\section{DISCUSSION}

From our review we were unable to specify the mechanisms of injury, except in the one child with a Type I Monteggia lesion who was injured by a direct blow to the mid-forearm, the so-called "night stick" injury (Polonsky 1956; Nand 1966; Reckling and Cordell 1968). It is generally accepted that indirect mechanisms, such as hyperpronation (Evans 1949) or hyperextension (Tompkins 1971), are probably responsible, but no such positions at the moment of injury could be recalled by the children in our series.

The traditional classification of Monteggia lesions by the direction of the displaced radial head may have some bearing on the mechanism of injury, but has no apparent relationship to the treatment or results in these paediatric patients. Consequently, while acknowledging both Monteggia's original classification and Bado's 
Table II. Simplified classification of Monteggia fractures

\begin{tabular}{|c|c|}
\hline & $\begin{array}{l}\text { Dislocation of } \\
\text { radial head }\end{array}$ \\
\hline Type I & Anterior ) \\
\hline Type II & Posterior $\}+$ Fracture of proximal ulna \\
\hline Type III & Lateral \\
\hline
\end{tabular}

more complex one, we propose simpler categories which encompass all variants (Table II). In all cases there is displacement of the radial head and a fracture of the proximal portion of the ulna.

As previously reported (Ramsey and Pedersen 1962), there is a fairly high incidence of Type III injuries in children; in our series it was $39 \%$. None of these fractures was difficult to treat, although it is noteworthy that 12 of the 18 Type III injuries had olecranon fractures.
The nerve injuries which may be associated with Monteggia fractures most commonly involve the radial or posterior interosseous nerves, because of their relation to the displaced head; the incidence of spontaneous recovery is high (Hunt 1939; Naylor 1942; Smith 1947; Spinner, Freundlich and Teicher 1968; Stein, Grabias and Deffer 1971).

Conclusions. The classification of Monteggia injuries need include only the three major types; the "equivalent" types and the Type IV, described by Bado, may be placed within Types I, II or III according to the direction of the radial head displacement. We also feel that radial head dislocation combined with an olecranon fracture deserves to be included in this classification.

Closed reduction is the preferred treatment in paediatric Monteggia lesions, and the results of treatment in this age group are generally favourable.

\section{REFERENCES}

Bado JL.The Monteggia lesion (translated by I. V. Ponseti). Springfield, Illinois: Charles C. Thomas, 1962;25-31.

Bado JL. The Monteggia lesion. Clin Orthop 1967;50:71-86.

Beddow FH, Corkery PH. Lateral dislocation of the radio-humeral joint with greenstick fracture of the upper end of the ulna. $J$ Bone Joint Surg [Br] 1960;42-B:782-4.

Boyd HB, Boals JC. The Monteggia lesion: a review of 159 cases. Clin Orthop 1969;66:94-100.

Bruce HE, Harvey JP Jr, Wilson JC Jr. Monteggia fractures. $J$ Bone Joint Surg $[$ Am] 1974;56-A: 1563-76.

Cunningham SR. Fracture of ulna with dislocation of head of radius. J Bone Joint Surg 1934;16:351-4.

Evans EM. Pronation injuries of the forearm with special reference to the anterior Monteggia fracture. J Bone Joint Surg [Br] 1949; 31-B: 578-88.

Germain JP. Fracture de Monteggia avec luxation latérale de la tête radiale. Union Med Can 1976;105:56-60.

Hume AC. Anterior dislocation of the head of the radius associated with undisplaced fracture of the olecranon in children. $J$ Bone Joint Surg [Br] 1957;39-B:508-12.

Hunt GH. Fracture of shaft of ulna, with dislocation of head of radius. JAMA 1939;112:1241-4.

Iselin F, Rigault P, Judet J. Fractures de Monteggia chez l'enfant. Presse Med 1966;74:2898-901.

Mullick S. The lateral Monteggia fracture. J Bone Joint Surg $[\mathrm{Am}]$ 1977;59-A:543-5.

Nand S. Clinical study of Monteggia fracture-dislocation. J Bone Joint Surg $[B r] 1966 ; 48-B: 198$.

Naylor A. Monteggia fractures. Br J Surg 1942;29:323-6.

Peiró A, Andres F, Fernandez-Esteve F. Acute Monteggia lesions in children. J Bone Joint Surg [Am] 1977;59-A:92-7.
Peltier LF. Eponymic fractures: Giovanni Battista Monteggia and Monteggia's fracture. Surgery 1957;42:585 91.

Polonsky AD. Monteggia fracture. J Bone Joint Surg $[\mathrm{Br}]$ 1956; 38- B : 593

Ramsey RH, Pedersen HE. The Monteggia fracture-dislocation in children: study of 15 cases of ulnar shaft fracture with radial head involvement. JAMA 1962:182:1091-3.

Reckling FW. Unstable fracture-dislocations of the forearm (Monteggia and Galeazzi lesions). J Bone Joint Surg [Am] 1982; 64-A:857-63.

Reckling FW, Cordell LD. Unstable fracture-dislocations of the forearm: the Monteggia and Galeazzi lesions. Arch Surg 1968; 96:999-1007.

Smith FM. Monteggia fractures: analysis of 25 consecutive fresh injuries. Surg Gynecol Obstet 1947;85:630-40.

Speed JS, Boyd HB. Treatment of fractures of ulna with dislocation of head of radius (Monteggia fracture). JAMA 1940;115: 1699-1705.

Spinner M, Freundlich BD, Teicher J. Posterior interosseous nerve palsy as a complication of Monteggia fractures in children. Clin Orthop 1968;58: 141-5.

Stein F, Grabias SL, Deffer PA. Nerve injuries complicating Monteggia lesions. J Bone Joint Surg [Am] 1971;53-A:1432 6.

Theodorou SD. Dislocation of the head of the radius associated with fracture of the upper end of the ulna in children. J Bone Joint Surg [Br] 1969;51-B: $700-6$.

Tompkins DG. The anterior Monteggia fracture: observations on etiology and treatment. J Bone Joint Surg [Am] 1971;53 A: 1 109-14.

Wiley JJ, Pegington J, Horwich JP. Traumatic dislocation of the radius at the elbow. J Bone Joint Surg [Br] 1974;56-B:501-7.

Wise RA. Lateral dislocation of the head of the radius with fracture of the ulna. J Bone Joint Surg 1941:23:379-81.

Wright PR. Greenstick fracture of the upper end of the ulna with dislocation of the radio-humeral joint or displacement of the superior radial epiphysis. J Bone Joint Surg [Br] 1963;45 B:727 31 . 